Published in Palmer $\mathrm{N}$ and Mills $\mathrm{A}$. Contracting-out health service provision in resource- and information-poor settings. In, Jones AM (ed) The Elgar Companion to Health Economics. Second Edition. Cheltenham: Edward Elgar Publishers, chp 23, pp 250-258, 2012. (paperback edition 2013)

\title{
Contracting-out health service provision in resource- and information-poor settings
}

\author{
Natasha Palmer Anne Mills
}

\section{Introduction}

The 'make or buy' question (Williamson 1985) in relation to the provision of publiclyfunded health services is posed frequently in resource-poor settings. Should a public bureaucracy be responsible for the provision of health services to the general public, or should the government contract-out the service provision function, while retaining responsibility for funding (Mills 1997)? Whilst this is a direct echo of debates in developed countries such as the UK, the different motivations and context of such a policy in countries which are both resource- and information-poor suggest that the approach, outcomes and implications are likely to diverge from those in wealthier settings. This chapter explores these issues, gives examples of the range of contracts and their uses, discusses how they can be evaluated and the nature of the evidence base, and identifies policy implications and research needs. 
Three key features of such settings affect the landscape for policy implementation, with implications for the type of contracts that can feasibly be used, and the manner in which they are likely to operate. First, whilst in many developed countries contracts are used as a mechanism to reshape service delivery, usually between existing parts of a public sector bureaucracy, resource-poor settings often employ them as a way of expanding service provision and bringing in new providers. Such providers are independent private entities, in contrast to the developed country providers who are not necessarily privately owned or profit-maximising (Bartlett and Le Grand 1993). Second, the public sector bureaucracy is usually weak and overstretched (Bennett and Mills 1998), with implications for its capacity both to provide services and to fulfil a stewardship role and act as informed purchaser (WHO 2000). Lack of government capacity also implies that the problem of "hidden information" (where uncertainty affects the performance of a task: see the chapter by Chalkley in this Companion) will be considerable for resourcepoor governments who lack information on the cost and quality of public and private service provision. Thirdly, most low income country governments are dependent to a considerable degree on external finance, and this means that the agenda of the donor community can play a role in determining national policy: in effect the donor may be the purchaser, at least during the period of project funding. Indeed, contracting-out service delivery to the private sector appears to be primarily favoured by the donor community rather than by countries: research recently undertaken for the UK Government's Department for International Development (DFID) has suggested that many governments actively distrust the for-profit private sector (Palmer 2005). A further implication of the involvement of international funding agencies is that it can open the local market to international contractors such as international non-government organisations (NGOs). 


\section{The motivation for contracting out}

Whether espoused by donor or government, the rationale for contracting-out service provision to the private sector is varied, ranging from the theoretical to the pragmatic. Theoretically, the arguments are broadly similar to those put forward within the approach known as 'New Public Management' in developed countries (Walsh 1995). The main objective is to improve efficiency of service provision and it is argued that either making clinics and hospitals residual claimants on revenues (Milgrom and Roberts 1992; Gauri, Cercone \& Briceno 2004), or exposing them to competitive markets through the establishment of renewable and competitive contracts, will achieve this aim. The idea of giving incentives to providers by making them more autonomous is less relevant in resource-poor settings, where providers are often private and autonomous. These private providers are commonly thought to be more efficient than public providers, though evidence on this, certainly at primary care level, is equivocal (Mills, Palmer, Gilson et al 2004).

Pragmatically, a number of arguments have favoured contracting-out policies. One key argument is that in many settings, public provision has failed altogether, or has widespread technical inefficiencies. For example poor drug supply systems result in health facilities lacking drugs for a good part of the year; poor human resource management and remuneration systems result in high rates of health worker absenteeism and poor service quality (Hanson et al 2003). Allocative efficiency is also judged to be poor: expenditure is skewed to hospitals, neglecting cost-effective primary care. There are also widespread inequalities: resource allocation (both funding and staff) favours 
urban areas. Thus there is scepticism on the willingness and ability of the public sector to improve technical and allocative efficiency through direct provision and hierarchical management.

Global attention has been focused on public sector failings, especially in SubSaharan Africa, by slow progress towards the UN Millennium Development Goals (MDGs) of reduced child and maternal mortality. For example, if use of proven effective childhood services rose from current low levels to $99 \%$, under-five deaths could fall by $63 \%$ (Jones et al 2003). Multilateral and bilateral agencies are thus seeking ways of rapidly 'scaling up' health services in a context of limited government capacity (Wagstaff and Claeson 2004). Contracting-out offers a means of getting round limited government absorptive capacity, and resistance to changing resource allocation patterns and health worker employment practices. For example, financial incentives for good performance may be more readily introduced in contracts with private agents than in public employment policies.

Another pragmatic argument is that resources already exist in the private sector both locally and globally and can be rapidly mobilised through contracts. Such resources include solo private practitioners, drug sellers, private hospitals, and NGOs such as church providers. The latter may already receive government subsidies, but without a formal contract. Evidence abounds that the majority of care-seeking, even for an important public health issue such as TB, is within the private sector (Uplekar, Pathania \& Raviglione 2001), so these providers are widely acceptable to the population - usually more so than public providers.

Finally, it is argued that NGOs are better suited to delivering certain types of services, notably socially and politically sensitive ones such as those related to HIV/AIDs. 
In some contexts, NGOs are argued to be more experienced and appropriate for working at community level, dealing with marginalised or at-risk populations, and addressing topics too sensitive for the government, such as illegal drug use.

Given these various contexts and motivations, the most common contractual arrangements are with private sector individuals, groups and organisations (for profit or not for profit) and for the provision of particular services and functions, across a defined geographical area. We refer to this as 'selective' contracting with the private sector, because even in its most extensive form (e.g. district-wide contracting in some parts of Cambodia) it still falls short of a universal system. While the purchaser is officially the government (national or local), in practice the contract is often initiated, funded and regulated by an external donor. In some cases the donor may be instrumental in creating the local public agency that acts as the purchaser.

\section{Approaches to contracting-out service provision in resource-poor settings}

A range of different types of services and functions can be contracted-out (Table 1). Recent years have seen a particular growth of contracting services to NGOs. Examples include contracting-out the management of public facilities e.g. in Cambodia, Afghanistan, Pakistan and Bangladesh; contracting community nutrition or health workers e.g. in Senegal and Madagascar (Marek et al 1999); and contracting-out a variety of preventive and palliative services related to HIV/AIDS, such as targeted services for high risk groups in Pakistan and India, and home-based care in South Africa. More 
traditionally, there have also been contracts with church hospitals in rural areas of many African countries e.g. Uganda, Malawi, Nigeria, Lesotho.

\section{INSERT TABLE 1 HERE}

Contracts vary considerably in formality and design. In some cases the contract is little more than the formalisation of a subsidy from government to ensure that private providers continue to provide services in underserved areas. In others, requirements may be more extensively specified, and payment may contain a performance-based element. The last few years have seen considerable development in the formality of contracts used, mainly driven by the procurement requirements of funding agencies.

\section{Contract evaluation}

Are any or all of these types of contract a good idea? This question is difficult to answer, and remarkably few attempts have been made to address it comprehensively. Contracts can be evaluated both directly and indirectly.

Direct evaluation can attempt to look at the performance of providers, or results achieved in terms of volume, efficiency and equity of service provision. These studies are difficult to conduct rigorously and few have been done. They are often hindered by the need to have similar data on the 'counterfactual', or the efficiency and equity of service provision by any alternative provider, who may not actually operate in the same setting. This means that there needs to be careful assessment of the study context in order 
to understand whether findings are more widely relevant. A recent review for the Cochrane Effective Practice and Organisation of Care Group (Lagarde and Palmer 2009) assessed the evidence on the effectiveness of contracting out healthcare services in improving access to care or health outcomes in low and middle income countries. There were only three studies that met the relatively stringent criteria of the Cochrane Library (Ali 2005, Bloom 2006, Lavadenz 2001) and these suggested that contracting out services could increase access and utilisation. However the authors of the review stress that the methodological weaknesses of these studies diminish the generalisability of their conclusions. A second review (Liu, Hotchkiss and Bose 2007) sought to take into account the effect of contracting out on other outcomes such as equity, quality and efficiency. They conclude that whilst contracting out has in many cases improved access, the evidence on these other dimensions of performance is unknown. In addition, the effect of contracting out on the overall system can be either positive or negative.

Where research which attempts to measure such outcomes is not possible, indirect methods of evaluation can still be used. In the early days of the UK's quasi-market reforms, Bartlett and Le Grand (1993) suggested that a theoretical analysis can be undertaken that specifies the conditions that services need to meet if they are to succeed, and then a preliminary empirical assessment made of the extent to which these conditions appear to have been met in practice. A second indirect line of enquiry examines the nature of contracts in practice, and whether they operate in the manner specified or foreseen (Palmer and Mills 2003; Palmer and Mills 2005). This literature draws on Macauley (1963) and MacNeil's (1978) work showing how contracts tend to become more relational and less transactional over time. In particular, it is suggested that contracts for health in resource-poor settings will tend to be relational where there are difficulties in 
specifying the services to be delivered and a lack of competition in the award of contracts (Palmer and Mills, 2005). This has implications for the way in which contracts will influence providers, and the ability of contracts to provide transparency and improve the efficiency or quality of service delivery. Since contracts are often justified on the grounds that they are an effective mechanism for providing incentives or controlling providers, questioning whether this appears to be the case is an indirect way of assessing the value of contracting-out.

The appropriate type of evaluation depends on the rationale for the contract in the first place. For example, a contract may be introduced to increase access to services rapidly and efficiently, to create incentives for existing providers to become more efficient, or to buy services that otherwise could not be provided by the public sector. Knowing to what extent contracting-out has been successful in each case implies a different type of evaluation. For example, where contracts are used to scale-up services where there is no public provision or to purchase services which the public sector is not able to provide, it is irrelevant to compare relative cost and efficiency between public and private providers. If a contract is made with private providers on the grounds that they will be more efficient, evaluation needs to compare their relative efficiency with that of possible alternative providers.

A further issue facing evaluation is what is feasible in terms of data collection or data availability. Many contracts in resource-poor countries have not been in place for very long, or the lack of data on service delivery can make them impossible to evaluate. An exception to the latter is the large externally funded contracting arrangements, some of which have provided a vehicle for research. 


\section{Examples of recent evaluations of contracting out}

This section selects several of the recent attempts to evaluate the performance of providers and the nature of contractual relationships, to give an in-depth insight into issues related to contracting-out service provision.

Two models of contracting for the delivery of district health services were piloted in rural Cambodia during 1998-2001 as part of a project funded by the Asian Development Bank. Districts were selected randomly and assigned either to "contractingout", “contracting-in", or controls. Under contracting-out, NGOs were given full responsibility for the delivery of specified services in a district, including drug procurement and hiring and firing of staff. Under contracting-in, NGOs worked within the existing system to strengthen district administrative structures. Control districts received no external support except a small subsidy towards service delivery. Equity as well as coverage targets for primary health care services were explicitly included in contracts. Pre- and post intervention household and facility survey data are available for evaluation of service delivery (Schwartz and Bhushan 2004a; Schwartz and Bhushan 2004b). Coverage of primary care services in all districts substantially increased over the study period, but all contracted districts outperformed control districts in terms of predefined coverage indicators such as immunization and attended deliveries. Contractedout models outperformed contracted-in. Much of the increase in health care utilisation in contracted districts was attributed to increased use by households of low socioeconomic status - children in the poorest $50 \%$ of households in the contracted districts were more likely to be fully immunized than those living in similar households in districts served by the government model of service provision (Schwartz and Bhushan 2004b). However, 
there may have been different resource flows to the different districts and the differences observed could be attributed to this. In addition it is unclear to what extent the NGOs that held these few contracts would be able to replicate this performance over a larger scale, or could be substituted by other NGOs.

A similar comparison between NGO and public sector service delivery has been attempted in Bangladesh (Mercer et al 2004). During 1998-2003, the Bangladesh Population and Health Consortium, supported by DFID, funded NGOs to deliver an essential package of services through their own clinics. NGOs reported their activities quarterly and their performance was evaluated using indicators such as the vaccination status of children and deliveries attended by a qualified person. Similarly compiled data from public sector clinics were not available, so to evaluate the performance of the NGOs, the authors compared selected health indicators with the latest estimates for Bangladesh, some of which covered earlier time periods. NGO data indicated high coverage of reproductive and child health services, and low levels of child mortality, in comparison to the rest of Bangladesh. Given the absence of any baseline data, it is not clear whether this was inherent to the areas where the NGOs were operating, although the authors attempted to control for this by tracking mortality rates: these demonstrated a clear drop since the commencement of contracts.

More recently there has been a larger scale and longer running introduction of contracting out in Afghanistan. After 2001, Afghanistan introduced a number of different contracting models as part of a strategy to increase access to a package of basic health services. A recent analysis (Arur et al 2010) finds that all forms of contracting in or contracting out were able to provide greater access to services than non-contracted 
facilities. However the authors note that overall utilisation of basic services in Afghanistan still remains at a very low per capita level (0.5-0.8 visits per annum).

In South Africa, a study evaluated the nature of contractual relationships between the state and private providers for primary care delivery, and found that formal aspects such as design, monitoring and resort to sanctions offered little control over the nature of the contractual outcome. In a contract with private GPs, individual, social and professional factors, and motivation, played an important role in determining the nature of service delivery under the contract (Palmer and Mills 2003). A comparison of three different contracts showed that an urban-based private sector contract for a sub-set of primary care services operated very differently from rural public sector contracts which attempted to provide broader health care coverage. Important environmental influences on contracts were highlighted, including the nature of the market, scope of services and involvement of a public purchaser (Palmer and Mills, 2005). The study suggests that service delivery under contract can be relatively unpredictable in a situation where contracts are not, or cannot be, closely specified. The lack of government capacity to specify and monitor contracts closely in many resource-poor settings emphasises the importance of this point.

Performance-based contracting has been suggested as one way of better aligning incentives so that problems of 'hidden information' are lessened, and the need for costly and difficult monitoring of performance reduced. A recent review of the evidence on performance-based payment has concluded that performance-based is a popular term but one that needs a clearer definition (Eldridge and Palmer 2009). It also highlights the risks associated with large scale use of performance-based incentives in fragile health systems, since achieving prescribed targets may not be within the control of providers, 
discouraging competition for service contracts in the most disadvantaged and difficult regions. There are also concerns over ensuring the reliability of information used to pay out bonuses in resource-poor settings.

Eichler, Auxila and Pollock (2001) reported the findings of a pilot scheme in Haiti (funded by the US Agency for International Development (USAID)) which introduced performance-based contracts for NGOs providing basic health services. Under the new system, which replaced a system of straightforward reimbursement for NGO expenditure, a portion $(5 \%)$ of the NGOs' historical budget was withheld but the opportunity was offered to earn that plus an additional $5 \%$ if performance targets were met. A one-year pilot showed marked improvements in performance. This type of approach was used in some of the models of contracting in Afghanistan.

Another evaluation which has attracted much attention, notably for its prospective, quasi-experimental design, is that of the impact of pay-for-performance to treatment facilities on the use and quality of prenatal, institutional delivery and child preventive care in Rwanda (Basinga et al 2010). In contrast to the Cambodian experience, comparison facilities had their input-based budgets increased to match the average payfor-performance payments to the intervention facilities, so separating the incentive effect from the resource effect. Pay-for-performance was found to have a large and significant positive impact on institutional deliveries, child preventive care visits, and quality of prenatal care, but not on number of prenatal care visits or immunisation rates. The authors suggest that these differences are probably due to the size of the financial incentives and the extent to which the provision of services is under the control of the provider rather than dependent on patient decisions. 


\section{Policy implications}

Studies have almost all suggested that contracting-out services can lead to improvement in service provision. However, caution is needed in assuming this holds everywhere, for three main reasons. Firstly, studies examine contracting-out in very specific settings, with little attention paid to the context in which they operate. This makes it very difficult to know to what extent the same benefits will be seen in different settings. In particular, some contracts apparently improved service delivery dramatically, but were introduced where public provision was virtually absent (eg Cambodia). Whether contracted-out services outperform a functioning public sector cannot be answered in such settings. In other studies there are problems of attributing the relative merits of contracted-out service delivery to the contracts per se, as opposed to unobserved factors.

Secondly, many contracting arrangements are externally funded, with strong design and management input, and of limited duration. Evaluations of locally initiated and managed arrangements, such as in Costa Rica (Gauri et al 2004) and South Africa (Palmer and Mills 2003), found that the contract did not appear to have a strong influence on service delivery and that many other aspects of the purchaser and provider were more important. This echoes some of the findings of long-term contractual relationships in developed countries (Flynn and Williams 1997). As yet there is no information on what might happen to externally funded and initiated contracting arrangements once the period of external funding ends.

Thirdly, most contracting-out is at the moment still only on a small scale, and it is unclear to what extent private providers currently involved are representative of a larger 
pool of potential contractors. There are uncertainties over whether there are enough technically capable and motivated NGOs or private providers to cover all parts of a country, and how limited competition might affect contract performance over time. The studies cited above demonstrate some of the difficulties in comprehensively evaluating the performance of contracts in resource-poor settings. If contracting-out is seen as an alternative to public sector provision, there is a need for some comparison between the two types of provider, but data on public sector service delivery is very scarce. Another problematic area is separating out delivery of a useful service such as community outreach from its roots in NGO provision: certain services currently delivered by NGOs are successful, but they may be equally so if they were delivered by government.

\section{Further research}

There remains a large agenda of further research. If the desirability of contracting-out as a reform prescription is to be more strongly established, a focus on the relative performance of different providers and contracting models needs to be complemented by better understanding of the dynamics of purchaser and provider relationships and contract management, and of the nature and size of local and global markets for contractors.

A further issue is the impact of contracting on the broader health system. A key difference in the types of contracts described here from those in an internal market are that both contracts and providers may be numerous and small scale, with little standardisation across a country. This runs the risk of fragmenting the health system and possibly creating substantial differences in provision from place to place. Other issues to

consider include how referrals operate in a contracted-out arrangement, how 
accountability can be guaranteed with a number of small-scale providers, and lastly the transaction costs of managing contracts in a resource-poor environment. There is no evidence on these issues.

In resource- and information-poor settings, external resources (both financial and technical) commonly support the purchasing role. It is as yet unclear what would occur if this support is withdrawn, whether governments can continue contracting on their own, and whether it is cost-effective for them to do so. One option which requires evaluation is contracting-out the purchasing function to a technically strong, independent body.

Governments often face a choice of type of provider. For example in South Africa, private GPs, NGOs, and commercial firms are all options for primary care contracts. On theoretical grounds, there may be a basis for preferring not-for-profit providers in a context of weak purchasing capacity since it is generally assumed that nonprofit organisations are more trustworthy and motivated to provide services in the public interest, but these assumptions require empirical testing.

\section{References}

Ali M S (2005). Innovative Health Management - Rahimyar Khan District. Islamabad: CIDA Devolution Support Project.

Arur A, Peters D, Hansen P, Mashkoor M, Steinhardt L and Burnham G (2010) Contracting for health and curative care use in Afghanistan between 2004 and 2005 Health Policy and Planning 25 135-144

Bartlett W and Le Grand J (1993) The Theory of Quasi-Markets in Le Grand J and Bartlett 
W (eds) Quasi Markets and Social Policy. Basingstoke: MacMillan

Basinga P, Gertler P, Binagwaho A, Soucat ALB, Sturdy JR, Vermeersch CMJ (2010) Paying Primary Health Care Centres for Performance in Rwanda. Policy Research Working Paper 5190. Washington DC: World Bank.

Bennett S and Mills A. (1998). Government capacity to contract: health sector experience and lessons. Public Administration and Development, 18: 307-326

Bloom G, Kremer M, King E, Bhushan I, Loevinsohn B and Schwartz J B (2006) Contracting for Health: evidence from Cambodia. Asian Development Bank, Washington DC; World Bank

Eichler R, Auxila P, Pollock J (2001) Output-Based Health Care: Paying for Performance in Haiti. World Bank Private Sector and Infrastructure Network, Note Number 236 Washington DC; World Bank

Eldridge C. and Palmer N. (2009) Performance based payment: some reflections on the discourse, evidence and unanswered questions. Health Policy and Planning 24: $160-6$

Flynn R. and Williams G. (1997) Contracting for health. Oxford: Oxford University Press 
Gauri V, Cercone J, Briceno R (2004) Separating financing and provision: evidence from 10 years of partnership with health cooperatives in Costa Rica. Health Policy and Planning 19(5):292-301

Hanson K, Ranson K, Oliveira-Cruz V and Mills A. (2003). Expanding Access to Health Interventions: A Framework for Understanding the Constraints to Scaling-Up. Journal of International Development 15 (1) 1-14.

Jones G., Steketee R.W., Black R.E., Bhutta Z.A., and Morris S.S. (2003). How many child deaths can we prevent this year? Lancet 362 (9377): 65-71.

Lagarde M and Palmer N (2009) The impact of contracting out on health outcomes and use of health services in low and middle-income countries (Review) Cochrane Database of systematic reviews 2009, Issue 4. Art. No: CD008133

Lavendenz F, Schwab N and Straatman H. (2001) Public, decentralized, and community health networks in Bolivia. Pan-American Review of Public Health, 9, 182-189.

Liu X, Hotchkiss D and Bose S. (2008) The effectiveness of contracting-out primary health care services in developing countries: a review of the evidence Health Policy and Planning 23: 1-12 
MacNeil, I. (1978) Contracts: adjustment of long-term economic relations under classical, neo-classical and relational law North Western University Law Review 72:854905

Macauley S (1963) Non contractual relations in business: A preliminary study American Sociological Review 28 (1): 55-67

Marek T, Diallo I, Ndiaye B, Rakotosalama J (1999) Successful contracting of prevention services: fighting malnutrition in Senegal and Madagascar. Health Policy and Planning 14(4):382-389

Mercer A, Hossain Khan M, Daulatuzzaman M, Reid J (2004) Effectiveness of an NGO primary health care programme in rural Bangladesh: evidence from the management information system. Health Policy and Planning 19 (4); 187-197.

Mills A. (1997). Improving the efficiency of public sector health services in developing countries: Bureaucratic versus market approaches. In Colclough C (ed) Marketizing Education and Health in Developing Countries: Miracle or Mirage? Oxford: Clarendon Press.

Mills A, Palmer N, Gilson L, McIntyre D, Schneider H, Sinanovic E, Wadee H (2004) The performance of different models of primary care provision in Southern Africa Social Science and Medicine 59; 931-943 
Milgrom P, Roberts J (1992) Economics, Organisation and Management New Jersey: Prentice-Hall

Palmer N (2005) Non state providers of basic services; the health sector. Presentation to DFID sponsored workshop on non state providers of basic services, Dubai, January 17-18, 2005

Palmer N, Mills A (2005) Contracts in the real world: case studies from Southern Africa. $\underline{\text { Social Science and Medicine 60(11): 2505-2514 }}$

Palmer N, Mills A. (2003) Classical versus relational approaches to understanding controls on a contract with independent GPs in South Africa Health Economics 12: $1005-1020$

Schwartz B and Bhushan I (2004a) Cambodia: Using Contracting to Reduce Inequity in Primary Health Care Delivery HNP Discussion Paper: Reaching the Poor Program Paper no. 3. Washington DC: World Bank

Schwartz B and Bhushan I (2004b) Improving immunization equity through a publicprivate partnership. WHO Bulletin 82 (9) 661-667

Uplekar J, Pathania V, Ravigione M (2001) Private practitioners and public health: weak links in tuberculosis control Lancet: 358; 912-916 
Wagstaff A and Claeson M (2004). The Millennium Goals for health: rising to the challenges. Washington DC: World Bank

Walsh K (1995) Public services and market mechanisms. Competition, contracting and the new public management. Basingstoke: Macmillan

WHO (2000). World Health Report 2000: Health systems: improving performance. Geneva: World Health Organisation

Williamson O. (1985) The Economic Institutions of Capitalism. Oxford: Oxford University Press 
Table 1: Services that may be contracted out

\begin{tabular}{||l|l||}
\hline Category & Examples \\
\hline Personal health services & hospital facility \\
& primary care facility \\
specific service \\
laboratory tests
\end{tabular}

